\title{
Difficult colonoscopy: air, carbon dioxide, or water insufflation?
}

\author{
Alisha Chaubal, Vikas Pandey, Ruchir Patel, Prateik Poddar, Aniruddha Phadke, Meghraj Ingle, Prabha \\ Sawant \\ Department of Gastroenterology, Lokmanya Tilak Municipal Medical College and General Hospital, Mumbai, India
}

Background/Aims: This study aimed to compare tolerance to air, carbon dioxide, or water insufflation in patients with anticipated difficult colonoscopy (young, thin, obese individuals, and patients with prior abdominal surgery or irradiation). Methods: Patients with body mass index (BMI) less than $18 \mathrm{~kg} / \mathrm{m}^{2}$ or more than $30 \mathrm{~kg} / \mathrm{m}^{2}$, or who had undergone previous abdominal or pelvic surgeries were randomized to air, carbon dioxide, or water insufflation during colonoscopy. The primary endpoint was cecal intubation with mild pain (less than 5 on visual analogue scale [VAS]), without use of sedation. Results: The primary end point was achieved in $32.7 \%, 43.8 \%$, and $84.9 \%$ of cases with air, carbon dioxide and water insufflation $(P<0.001)$. The mean pain scores were $5.17,4.72$, and 3.93 on the VAS for air, carbon dioxide, and water insufflation $(P<0.001)$. The cecal intubation rate or procedure time did not differ significantly between the 3 groups. Conclusions: Water insufflation was superior to air or carbon dioxide for pain tolerance. This was seen in the subgroups with BMI $<18 \mathrm{~kg} / \mathrm{m}^{2}$ and the post-surgical group, but not in the group with BMI $>30 \mathrm{~kg} / \mathrm{m}^{2}$. (Intest Res 2018;16:299-305)

Key Words: Colonoscopy; Insufflation; Carbon dioxide insufflation; Water immersion

\section{INTRODUCTION}

There are groups whose colonic anatomy predicts difficult colonoscopy, i.e., they experience more pain and require sedation. This includes individuals who are very thin, or obese, or who have undergone open abdominal and pelvic surgeries. ${ }^{1}$ Sedation increases the post-procedure recovery time, and the anaesthetic agents may also cause adverse drug reactions. ${ }^{2}$ Hence, at Lokmanya Tilak General Hospital we try to minimize the use of sedation during colonoscopy. Studies have shown that water is better than air or carbon dioxide insufflation in terms of patient tolerance..$^{3-5}$ However, these methods have not been studied exclusively in patients with anticipated difficult colonoscopy. In our study we compared the 3 insufflation methods with respect to pain experienced

Received April 25, 2017. Revised May 26, 2017. Accepted June 26, 2017. Published online November 10, 2017

Correspondence to Alisha Chaubal, Department of Gastroenterology, Lokmanya Tilak Municipal Medical College and General Hospital, Mumbai 400022, India. Tel: +91-22-2406-3077,E-mail: alishachaubal@gmail.com during the procedure, cecal intubation rate and time and use of maneuvers during colonoscopy.

\section{METHODS}

\section{Subjects}

This was an experimental study carried out at a tertiary care hospital in Mumbai from December 2014 to October 2016. The procedures followed were in accordance with the ethical standards of the Helsinki Declaration of 1975, as revised in 2000. The study was approved by the Hospital Review Board of Lokmanya Tilak General Hospital (IRB number: IEC-15/2014). Written informed consent was obtained from all patients before enrolment into the study. Patients with anticipated difficult colonoscopies were included and divided into 3 groups: (1) individuals with BMI $<18 \mathrm{~kg} / \mathrm{m}^{2}$, (2) individuals with BMI $>30 \mathrm{~kg} / \mathrm{m}^{2}$, or (3) individuals who had undergone abdominal or pelvic surgery (other than

๑ Copyright 2018. Korean Association for the Study of Intestinal Diseases. All rights reserved.

This is an Open Access article distributed under the terms of the Creative Commons Attribution Non-Commercial License (http://creativecommons.org/licenses/by-nc/4.0)

which permits unrestricted non-commercial use, distribution, and reproduction in any medium, provided the original work is properly cited. 
colonic). The exclusion criteria were age less than 18 years, or presence of renal or cardiopulmonary disease. These patients were allocated to air, water, or carbon dioxide insufflation by a computer generated random number table. Sedation was given upon patient's request. Only patients with bowel preparation grade $>5$ on the Boston bowel preparation scale and without any colonic obstruction precluding complete colonoscopy were included in the final analysis. ${ }^{6}$ The primary endpoint was cecal intubation with pain score (visual analogue scale, VAS) $<5$ (moderate pain) without sedation. Secondary outcomes were cecal intubation rate and time, pain scores at the rectosigmoid junction, splenic flexure, hepatic flexure, and during withdrawal, and use of other maneuvers such as pressure and change of position during colonoscopy. Subgroup analyses for primary and secondary end points were carried out in the 3 study groups: $\mathrm{BMI}<18$ $\mathrm{kg} / \mathrm{m}^{2}$, BMI $>30 \mathrm{~kg} / \mathrm{m}^{2}$, and post-surgical cases.

\section{Study Procedure}

This was a randomized, experimental study of the patients undergoing colonoscopy at our center and fulfilling the above inclusion and exclusion criteria. Procedures were performed by 2 endoscopists experienced in colonoscopy for 2 years. Each had performed at least 400 colonoscopies before the study. Patients took a low-volume split-dose preparation regimen of $2 \mathrm{~L}$ of polyethylene glycol. Half the dose was taken at night before the procedure, and the rest in the morning. ${ }^{7}$ Demographic data (age, sex, and BMI), previous abdominal surgery, main indication for colonoscopy, comorbidities, and current medications was recorded. The VAS for pain was explained before the procedure and patients were asked to give feedback during the procedure when asked. Colonoscopy was performed in the left lateral position without sedation. An Olympus series CV-150 (Tokyo, Japan) colonoscope was used. Alphaflator (Om surgicals, Mumbai, India) with maximum pressure of $45 \mathrm{mmHg}$ and flow rate of $25 \mathrm{~L} / \mathrm{min}$ was used for carbon dioxide insufflation. Endopump (Mitra Industries Pvt. Ltd., Faridabad, India) with a capacity of $5 \mathrm{~L}$ was used for water insufflation. Water used was at room temperature, i.e., $32^{\circ} \mathrm{C}$ to $37^{\circ} \mathrm{C}$. Cecal intubation was defined as passage of the colonoscope into the cecum with visualization of the cecal wall and appendiceal orifice. Cecal intubation time was defined as the time for passage of the colonoscope from the anus to the cecum to the closest minute. During withdrawal, air was used for air and water insufflation and carbon dioxide for carbon dioxide insufflation. Withdrawal was defined as the time for passage of the colonoscope from the cecum to the rectum. Withdrawal time took at least 6 minutes was taken. ${ }^{8}$ Pain was recorded by an assistant at the rectosigmoid junction, splenic flexure, hepatic flexure, and during withdrawal, using the VAS (0, no pain; 5 , moderate pain; and 10 , unbearable pain). ${ }^{9}$ A note was made of abdominal pressure and change of position during the procedure. The pain score was calculated as an average for all patients reported at the corresponding flexure or bend. Sedation was induced on demand. Patients with poor bowel preparation (Boston bowel preparation scale $\leq 5$ ) and those with colonic obstruction prior to cecal intubation were not included in the final analysis.

\section{Study Endpoints}

The primary endpoint was successful cecal intubation with pain score less than 5 on the VAS (mild pain), without sedation. Secondary outcomes were cecal intubation rate, cecal intubation time, pain scores at the rectosigmoid junction, splenic flexure, hepatic flexure, and during withdrawal, and use of maneuvers such as abdominal pressure and change of position.

\section{Statistical Analysis}

Statistical analyses were performed using SPSS version 22.0 (IBM Corp., Armonk, NY, USA). $P$-values $<0.05$ were considered statistically significant. Demographics (age and sex) were compared between insufflation groups using Pearson's chi-square contingency table, and BMI was compared using one-way ANOVA with post hoc analysis (Sidak correction). The primary end point, cecal intubation rate, abdominal compression, and change of position were compared for insufflation groups using Pearson chi-square contingency table. The mean pain score, pain scores at the rectosigmoid junction, splenic flexure, hepatic flexure, and during withdrawal were compared using one-way ANOVA with post hoc analysis (Sidak correction).

\section{RESULTS}

\section{Patient's Characteristics}

A total of 167 patients (air, 56; carbon dioxide, 56; and water, 55) met the inclusion criteria for the study. Of these, 158 had adequate bowel preparation, i.e., Boston bowel preparation scale $>5$ (air, 54; carbon dioxide, 51; and water, 53). Five patients had colonic narrowing due to stricture/mass 
precluding complete colonoscopy (air, 2 and carbon dioxide, 3 ). Hence, 153 patients were included in the final analysis (air, 52; carbon dioxide, 48; and water, 53). Patient characteristics and subgroup distributions (BMI $<18 \mathrm{~kg} / \mathrm{m}^{2}$ or $>30 \mathrm{~kg} /$ $\mathrm{m}^{2}$, and post-surgical) were comparable in the air, carbon dioxide, and water insufflation groups. However, the carbon dioxide group had a higher percentage of females (Fig. 1, Supplementary Tables 1 and 2).

\section{Overall Analysis}

\section{1) Primary End Point}

The primary end point (no sedation, cecal intubation, VAS score $<5$ ) was reached in $32.7 \%, 43.8 \%$, and $84.9 \%$ of patients in the air, water, and carbon dioxide insufflation groups, respectively $(P<0.001$, water being significantly better than air $[P<0.001]$, and carbon dioxide $[P=0.001])$.

\section{2) Mean Pain Score}

The mean pain scores were 5.17, 4.72, and 3.93 on the VAS for air, carbon dioxide, and water insufflation groups respectively $(P<0.001)$, with significant differences between water and air $(P<0.001)$ and water and carbon dioxide $(P=0.001)$, but not carbon dioxide and air insufflation groups $(P=0.090)$.

\section{3) Sedation}

Sedation was required in $9.6 \%, 14.6 \%$, and $3.8 \%$ of the patients in the air, carbon dioxide and water insufflation groups respectively $(P=0.110)$.

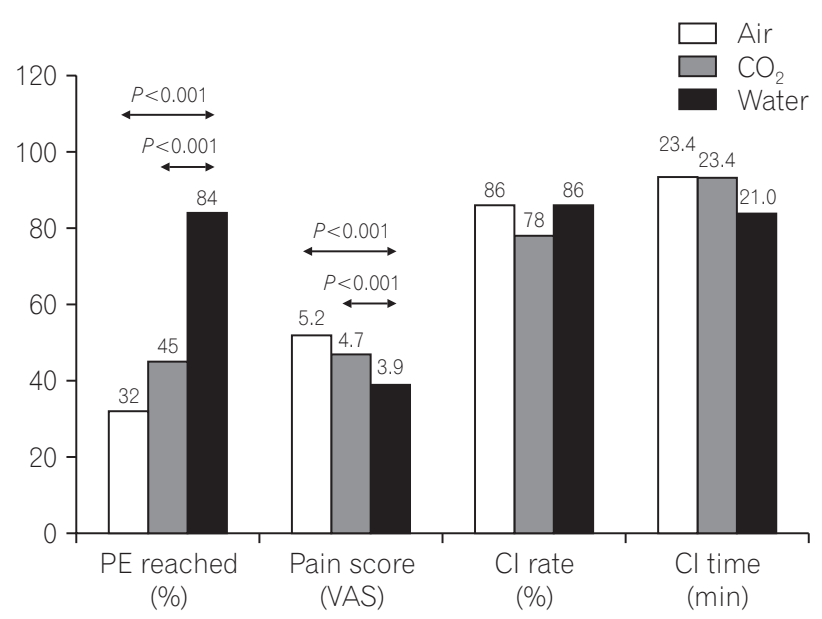

Fig. 1. Overall analysis of primary end (PE) point, mean pain score, cecal intubation $(\mathrm{Cl})$ rate, $\mathrm{Cl}$ time in air, carbon dioxide, and water insufflation groups. VAS, visual analogue scale.

\section{4) Logistic Regression Analysis}

Logistic regression analysis showed that BMI was the only independent predictor of achieving the primary end point.

\section{Secondary End Points}

\section{1) Cecal Intubation Rate and Time}

Cecal intubation rate was not significantly different for air (86.5\%), carbon dioxide $(77.1 \%)$, or water $(84.9 \%)(P=0.450)$ insufflation groups. After sedation this increased to $96 \%$, $92 \%$, and $90 \%$ for air, carbon dioxide, and water insufflation groups, respectively. Two patients in the water group and 2 patients in the carbon dioxide group required change of method to air.

Cecal intubation time was 23.42, 23.35 and 21.00 minutes for air, carbon dioxide, and water insufflation groups, respectively $(P=0.140)$.

\section{2) Flexural Pain Scores}

Mean VAS pain scores at the rectosigmoid junction were $5.81,5.95$, and 4.65 for air, carbon dioxide, and water insufflation groups, respectively $(P<0.001)$, with water being significantly better than both air and carbon dioxide $(P<0.001)$. At the splenic flexure score, the VAS scores were 6.36, 5.65, and 4.69 for air, carbon dioxide, and water insufflation groups, respectively $(P<0.001)$, with water being significantly better than both air $(P<0.001)$ and carbon dioxide $(P=0.018)$. At the hepatic flexure the VAS pain scores were $3.57,3.00$, and 2.69 for air, carbon dioxide, and water insufflation groups, respectively $(P=0.006)$, with water being significantly better than air $(P=0.005)$ but not carbon dioxide $(P=0.110)$. During withdrawal the VAS pain scores were 1.81, 1.25, and 1.89 for air, carbon dioxide, and water insufflation groups, respectively $(P<0.001)$, with carbon dioxide being significantly better than air $(P=0.001)$ and water $(P<0.001)$.

\section{3) Abdominal Compression}

Pressure was required in $69.2 \%, 60.4 \%$, and $50.9 \%$ of the patients in the air, carbon dioxide, and water insufflation groups, respectively $(P=0.160)$.

\section{4) Change of Position}

Change of position was required in 59.6\%, 66.7\%, and $58.5 \%$ of the patients in the air, carbon dioxide, and water insufflation groups, respectively $(P=0.760)$. 


\section{Subgroup Analysis}

\section{1) $\mathrm{BMI}<18 \mathrm{~kg} / \mathrm{m}^{2}$}

The primary end point was reached in $7.1 \%, 31.3 \%$, and $82.4 \%$ of the patients in the air, carbon dioxide, and water insufflation groups, respectively $(P<0.001)$, water being significantly better than air $(P<0.001)$ and carbon dioxide $(P=0.003)$. Mean pain scores were $5.28,5.12$, and 3.64 for air, carbon dioxide, and water insufflation groups, respectively $(P<0.001)$, with water being significantly better than both air $(P<0.001)$ and carbon dioxide $(P<0.001)$. Sedation was required in $28.6 \%, 25.0 \%$, and $11.8 \%$ of the patients in the air, carbon dioxide, and water insufflation groups, respectively $(P=0.470)$. At the rectosigmoid junction, the VAS score were $6.00,6.00$, and 4.18 for the air, carbon dioxide, and water insufflation groups, respectively $(P<0.001)$, with water being significantly better than both air $(P=0.002)$ and carbon dioxide $(P=0.001)$. At the splenic flexure, the VAS scores were $7.29,6.81$, and 4.63 for air, carbon dioxide, and water insufflation groups, respectively $(P<0.001)$, with water being significantly better than both air $(P<0.001)$ and carbon dioxide $(P=0.001)$. At the hepatic flexure, the VAS scores were 3.60, 2.73, and 2.43 for air, carbon dioxide, and water insufflation groups, respectively $(P=0.090)$. During withdrawal, the VAS scores were 1.90, 1.20, and 1.73 for air, carbon dioxide, and water insufflation groups, respectively $(P=0.080)$. Pressure was required in $92.8 \%, 68.8 \%$, and $35.3 \%$ of the patients in the air, carbon dioxide, and water insufflation groups, respectively $(P=0.010)$, with significantly less pressure required with water as compared to air $(P=0.003)$. Change of position was required in $28.6 \%, 43.8 \%$, and $29.4 \%$ of the patients in the air,

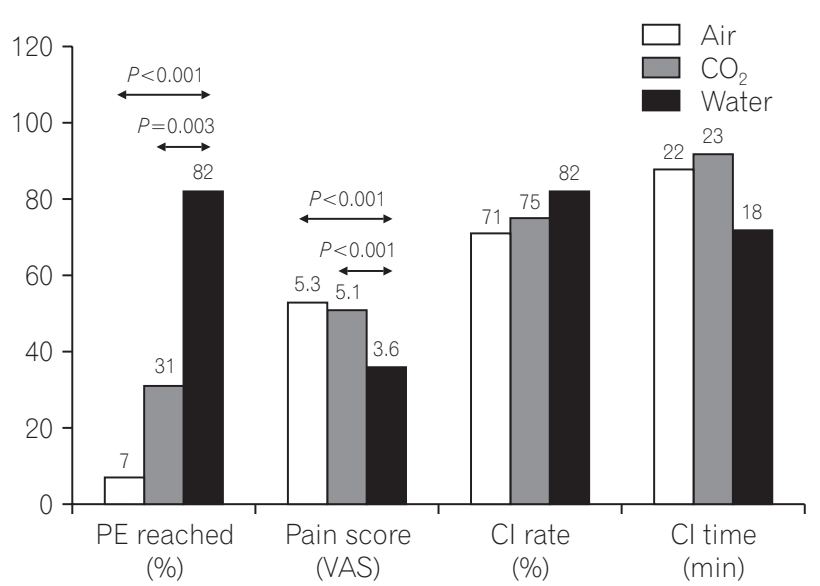

Fig. 2. Analysis of primary end (PE) point, mean pain score, cecal intubation $(\mathrm{Cl})$ rate, $\mathrm{Cl}$ time in air, carbon dioxide, and water insufflation groups in $\mathrm{BMI}<18 \mathrm{~kg} / \mathrm{m}^{2}$. VAS, visual analogue scale. carbon dioxide, and water insufflation groups, respectively $(P=0.600)$ (Fig. 2, Supplementary Table 3).

\section{2) $\mathrm{BMI}>30 \mathrm{~kg} / \mathrm{m}^{2}$}

The primary end point was reached in $46.7 \%, 56.3 \%$, and $78.6 \%$ of the patients in the air, carbon dioxide, and water insufflation groups, respectively $(P=0.750)$. The VAS scores were $4.92,4.22$, and 4.11 for air, carbon dioxide, and water insufflation groups, respectively $(P=0.100)$. Sedation was not used in any of the groups. At the rectosigmoid junction the VAS scores were $5.85,5.44$, and 5.33 for air, carbon dioxide, and water insufflation groups, respectively $(P=0.500)$. At the splenic flexure, the VAS scores were 5.62, 4.78, and 4.33 for air, carbon dioxide, and water insufflation groups, respectively $(P=0.015)$, with water being significantly better than air $(P=0.016)$ but not carbon dioxide $(P=0.715)$. At the hepatic flexure, the VAS scores were $3.31,3.67$, and 3.00 for air, carbon dioxide, and water insufflation groups, respectively $(P=0.700)$. During withdrawal, the VAS scores were 1.92, 1.50, and 2.38 for air, carbon dioxide, and water insufflation groups, respectively $(P=0.100)$. Pressure was required in $60.0 \%, 68.7 \%$ and $64.3 \%$ of the patients in the air, carbon dioxide and water insufflation groups, respectively $(P=0.870)$. Change of position was required in $60.0 \%, 68.7 \%$, and $57.1 \%$ of the patients in the air, carbon dioxide and water insufflation groups, respectively ( $P=0.780$ ) (Fig. 3, Supplementary Table 4).

\section{3) Post-Surgery Group}

The primary end point was reached in $39.1 \%, 50.0 \%$, and $77.3 \%$ of the patients in the air, water, and carbon dioxide

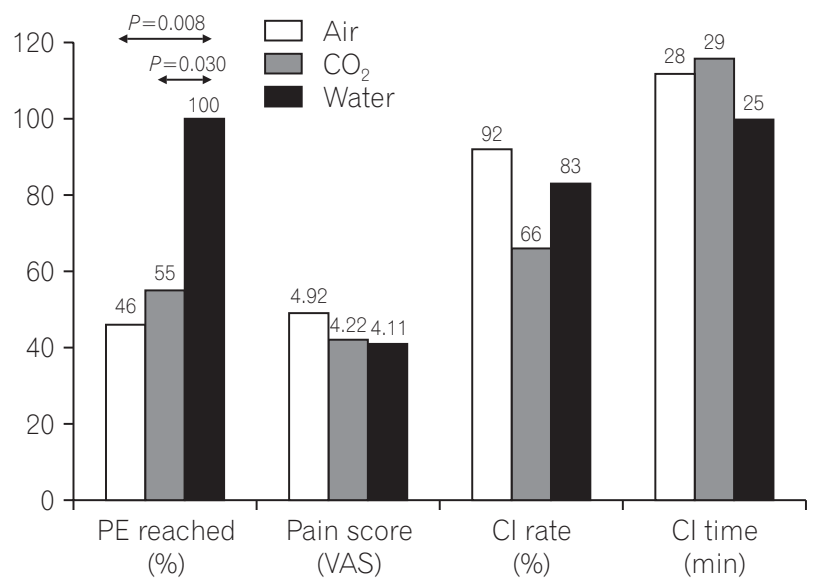

Fig. 3. Analysis of primary end (PE) point, mean pain score, cecal intubation $(\mathrm{Cl})$ rate, $\mathrm{Cl}$ time in air, carbon dioxide, and water insufflation groups in $\mathrm{BMI}>30 \mathrm{~kg} / \mathrm{m}^{2}$. VAS, visual analogue scale. 


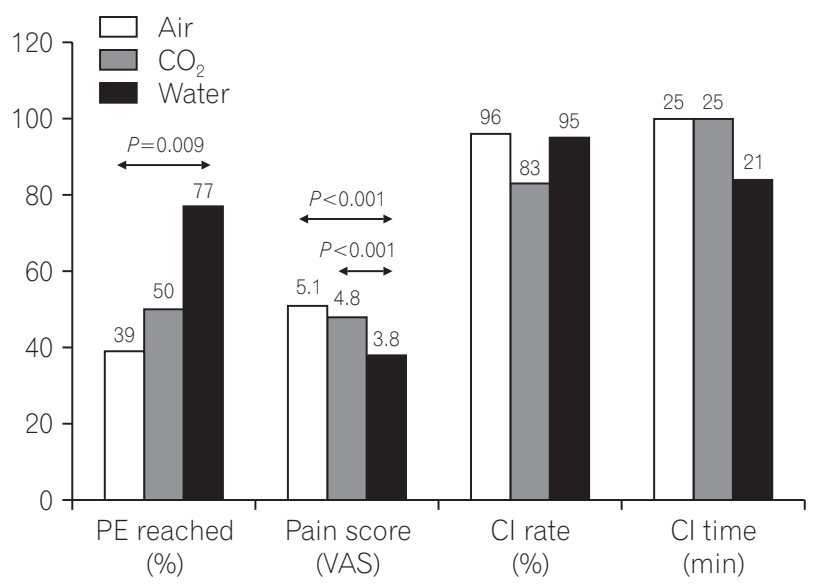

Fig. 4. Analysis of primary end (PE) point, mean pain score, cecal intubation $(\mathrm{Cl})$ rate, $\mathrm{Cl}$ time in air, carbon dioxide, and water insufflation groups in post-surgery group. VAS, visual analogue.

groups respectively $(P=0.031)$, water being significantly better than air $(P=0.009)$ but not carbon dioxide $(P=0.072)$. Mean pain scores were 5.11, 4.80, and 3.81 in the air, carbon dioxide, and water insufflation groups, respectively $(P<0.001)$, with water being significantly better than both air $(P<0.001)$ and carbon dioxide $(P<0.001)$. Sedation was induced in $21.7 \%, 22.2 \%$, and $13.6 \%$ of the patients in the air, carbon dioxide and water insufflation groups, respectively $(P=0.720)$. At the rectosigmoid junction, the VAS scores were $5.93,5.80$, and 4.58 for air, carbon dioxide and water insufflation groups, respectively $(P<0.001)$, with water being significantly better than both air $(P<0.001)$ and carbon dioxide $(P=0.003)$. At the splenic flexure, the VAS scores were 6.48, 6.08 , and 4.52 for air, carbon dioxide and water insufflation groups, respectively $(P<0.001)$, with water being significantly better than both air $(P<0.001)$ and carbon dioxide $(P=0.001)$. At the hepatic flexure, the VAS scores were $3.43,3.00$, and 2.64 for air, carbon dioxide and water insufflation groups, respectively $(P=0.150)$. During withdrawal, the VAS scores were $1.91,1.29$, and 1.96 for air, carbon dioxide, and water insufflation groups, respectively $(P=0.010)$, with carbon dioxide being significantly better than air $(P=0.030)$ and water $(P=0.020)$. Pressure was required in $60.9 \%, 38.9 \%$, and $54.5 \%$ of the patients in the air, carbon dioxide, and water insufflation groups, respectively $(P=0.364)$. Change of position was required in $78.2 \%, 77.8 \%$, and $81.8 \%$ of the patients in the air, carbon dioxide, and water insufflation groups, respectively $(P=0.939)$ (Fig. 4, Supplementary Table 5).

\section{DISCUSSION}

Studies comparing insufflation techniques have found water-aided colonoscopy to be better tolerated by patients than either air or carbon dioxide insufflation. However, these were done without discriminating difficult colonoscopies from others. Few studies have exclusively assessed the superiority of insufflation methods in difficult colonoscopies. Difficult anatomy for colonoscopy has been broadly classified into 2 types: the narrow, angulated colon and the redundant colon. ${ }^{10}$ In a study by Takahashi et al. ${ }^{1}$ of 848 patients undergoing colonoscopy, it was observed that lower BMI, younger age, intubation time, preparation status, and previous gynecologic surgery were predictors of difficult cecal intubation. Having a lower BMI or previous pelvic surgery predisposes the patient to a narrower, angulated distal colon. ${ }^{11}$ In the obese patient, cecal intubation has been found to be prolonged due to excessive looping and the requirement of maneuvers and even a prone position to complete colonoscopy. ${ }^{12}$ In our study, we included 3 groups of the patients with anticipated difficult colonoscopies: patients with BMI less than $18 \mathrm{~kg} / \mathrm{m}^{2}$ and more than $30 \mathrm{~kg} / \mathrm{m}^{2}$ and patients who had undergone non-colonic abdominal or pelvic surgery. We subjected them to either air, water, or carbon dioxide insufflation, and studied the pain scores at each flexure, along with the cecal intubation time and rate.

Air insufflation causes pain during intubation as it elongates and distends the colon. Water insufflation reduces pain by weighing down the sigmoid, hence straightening it and decreasing colonic spasm. ${ }^{13,14}$ Water-aided colonoscopy is of 2 types: water immersion, in which water is infused at insertion and removed during withdrawal, and water exchange, in which both infusion and suction of water are performed during insertion to minimize distension. Water exchange has been shown to be superior to water immersion, causing less pain and minimizing the sedation requirement. ${ }^{15,16}$ In our study, we used the water immersion technique, as it had a smaller learning curve as compared to water exchange, and the study was performed by trainees. We found that $9 \%$ of the patients in the air group required sedation as opposed to $2.2 \%$ in the water group.

Carbon dioxide insufflation can reduce gas combustion. ${ }^{17}$ It is absorbed 150 times faster than nitrogen from the bowel, resulting in less pain and ischemia. ${ }^{18}$ Castell reviewed 21 randomized controlled trials comparing air and carbon dioxide insufflation, and observed that there was reduced pain and faster cecal intubation in the carbon dioxide group. ${ }^{19} \mathrm{We}$ did not obtain similar results in our study. In a randomized 
controlled trial by Garborg et al., ${ }^{3}$ carbon dioxide insufflation was compared with water exchange and water insufflation, and was associated with less pain. ${ }^{20}$ We had similar results in our study. A few studies have compared insufflation methods in patients with anticipated difficult colonoscopy.

Luo et al. ${ }^{21}$ studied patients who had undergone previous abdominal or pelvic surgery. Water insufflation showed better cecal intubation rates (92.7\% vs. $76.4 \%)$ and lower pain scores ( $2.1 \pm 1.8$ vs. $4.6 \pm 1.7)$, as compared to air. ${ }^{22}$ In our study, we observed that pain scores were lower for water as compared to air or carbon dioxide, but the cecal intubation rate did not differ between the 3 groups. Patients with a low BMI, i.e., $<18 \mathrm{~kg} / \mathrm{m}^{2}$, and those who have undergone pelvic surgery tend to have a sharply-angulated left colon. Both these groups benefit from water-aided colonoscopy, as it straightens the left colon. Vemulapalli and $\operatorname{Rex}^{20}$ evaluated patients with redundant colons and found less need for maneuvers in the water immersion group. We did not find significant differences in achieving primary endpoints in the group with BMI $>30 \mathrm{~kg} / \mathrm{m}^{2}$. The obese patients tend to have redundant colons that permit loop formation in both sigmoid and transverse colons. Water-aided colonoscopy tends to straighten the left colon but might not reduce transverse colon loop formation. Since we did not objectively assess loop formation in the study, we cannot verify these assumptions. Although the primary endpoints were more often achieved with water-aided colonoscopy $(46.7 \%, 56.3 \%$, and $78.6 \%$ in the air, carbon dioxide, and water insufflation groups; $P=0.750$ ), the difference was not significant. We found that frequent abdominal compression and change of position was required to complete the colonoscopy, irrespective of the method of insufflation.

In our study, we compared the pain scores at each bend, instead of determining a total score, and found that negotiation of the left colon was better tolerated in the water insufflation group, whereas pain score at the hepatic flexure did not differ between the 3 groups.

We observed that the use of carbon dioxide during withdrawal resulted in less pain, as compared to the use of air on withdrawal. This correlates with the findings of a study by Cadoni et al. ${ }^{22}$

The limitations of our study are that the colonoscopists were not blinded and the carbon dioxide group included more women than the other 2 groups. Our study highlights techniques in anticipated difficult colonoscopies. This will aid in choosing appropriate insufflation techniques in clinical practice.

In conclusions, water insufflation was superior to air or carbon dioxide insufflation for pain tolerance in the left colon. This trend was seen in the subgroup with BMI $<18 \mathrm{~kg} /$ $\mathrm{m}^{2}$ and the post-surgical group, but not in the group with BMI $>30 \mathrm{~kg} / \mathrm{m}^{2}$. The cecal intubation rate or time did not significantly differ across the insufflation groups. The group with BMI $>30 \mathrm{~kg} / \mathrm{m}^{2}$ frequently required use of maneuvers for colonoscopy completion.

\section{FINANCIAL SUPPORT}

The authors received no financial support for the research, authorship, and/or publication of this article.

\section{CONFLICT OF INTEREST}

No potential conflict of interest relevant to this article was reported.

\section{REFERENCES}

1. Takahashi Y, Tanaka H, Kinjo M, Sakumoto K. Prospective evaluation of factors predicting difficulty and pain during sedationfree colonoscopy. Dis Colon Rectum 2005;48:1295-1300.

2. Takahashi Y, Tanaka H, Kinjo M, Sakumoto K. Sedation-free colonoscopy. Dis Colon Rectum 2005;48:855-859.

3. Garborg K, Kaminski MF, Lindenburger W, et al. Water exchange versus carbon dioxide insufflation in unsedated colonoscopy: a multicenter randomized controlled trial. Endoscopy 2015;47:192-199.

4. Cadoni S, Gallittu P, Sanna S, et al. A two-center randomized controlled trial of water-aided colonoscopy versus air insufflation colonoscopy. Endoscopy 2014;46:212-218.

5. Ramirez FC, Leung FW. A head-to-head comparison of the water vs. air method in patients undergoing screening colonoscopy. J Interv Gastroenterol 2011;1:130-135.

6. Lai EJ, Calderwood AH, Doros G, Fix OK, Jacobson BC. The Boston bowel preparation scale: a valid and reliable instrument for colonoscopy-oriented research. Gastrointest Endosc 2009;69(3 Pt 2):620-625.

7. Martín-Noguerol E, González-Santiago JM, Martínez-Alcalá C, et al. Split-dose sodium picosulphate/magnesium citrate for morning colonoscopies performed 2 to 6 hours after fluid intake. Gastroenterol Hepatol 2013;36:254-260.

8. Rex DK, Petrini JL, Baron TH, et al. Quality indicators for colonoscopy. Am J Gastroenterol 2006;101:873-885.

9. McCormack HM, Horne DJ, Sheather S. Clinical applications of visual analogue scales: a critical review. Psychol Med 1988;18:1007-1019. 
10. Rex DK. Achieving cecal intubation in the very difficult colon. Gastrointest Endosc 2008;67:938-944.

11. Anderson JC, Messina CR, Cohn W, et al. Factors predictive of difficult colonoscopy. Gastrointest Endosc 2001;54:558-562.

12. Desormeaux MP, Scicluna M, Friedland S. Colonoscopy in obese patients: a growing problem. Gastrointest Endosc 2008;67:AB89-AB90.

13. Anderson JC. Water-aided colonoscopy. Gastrointest Endosc Clin N Am 2015;25:211-226.

14. Leung JW, Thai A, Yen A, et al. Magnetic endoscope imaging (ScopeGuide) elucidates the mechanism of action of the painalleviating impact of water exchange colonoscopy: attenuation of loop formation. J Interv Gastroenterol 2012;2:142-146.

15. Cadoni S, Sanna S, Gallittu P, et al. A randomized, controlled trial comparing real-time insertion pain during colonoscopy confirmed water exchange to be superior to water immersion in enhancing patient comfort. Gastrointest Endosc 2015;81:557566.

16. Leung JW, Mann SK, Siao-Salera R, et al. A randomized, controlled comparison of warm water infusion in lieu of air insufflation versus air insufflation for aiding colonoscopy insertion in sedated patients undergoing colorectal cancer screening and surveillance. Gastrointest Endosc 2009;70:505-510.
17. Becker GL. The prevention or gas explosions in the large bowel during electrosurgery. Surg Gynecol Obstet 1953;97:463-467.

18. Williams CB. Who's for CO2? Gastrointest Endosc 1986;32:365367.

19. Sajid MS, Caswell J, Bhatti MI, Sains P, Baig MK, Miles WF. Carbon dioxide insufflation vs conventional air insufflation for colonoscopy: a systematic review and meta-analysis of published randomized controlled trials. Colorectal Dis 2015;17:111-123.

20. Vemulapalli KC, Rex DK. Water immersion simplifies cecal intubation in patients with redundant colons and previous incomplete colonoscopies. Gastrointest Endosc 2012;76:812-817.

21. Luo H, Zhang L, Liu X, et al. Water exchange enhanced cecal intubation in potentially difficult colonoscopy. Unsedated patients with prior abdominal or pelvic surgery: a prospective, randomized, controlled trial. Gastrointest Endosc 2013;77:767773.

22. Cadoni S, Falt P, Gallittu P, Liggi M, Smajstrla V, Leung FW. Impact of carbon dioxide insufflation and water exchange on postcolonoscopy outcomes in patients receiving on-demand sedation: a randomized controlled trial. Gastrointest Endosc 2017;85:210-218.e1. 
See "Difficult colonoscopy: air, carbon dioxide, or water insufflation?" on page 299.

Supplementary Table 1. Patient Characteristics

\begin{tabular}{|c|c|c|c|c|}
\hline Characteristic & Air insufflation $(n=52)$ & Carbon dioxide insufflation $(n=48)$ & Water insufflation $(n=53)$ & $P$-value \\
\hline Age $(y r)$ & 46.10 & 46.70 & 44.06 & 0.80 \\
\hline \multicolumn{5}{|l|}{ Sex } \\
\hline Male & $27(52)$ & $12(25)$ & $27(52)$ & 0.02 \\
\hline Female & $25(48)$ & $36(75)$ & $26(48)$ & 0.02 \\
\hline \multicolumn{5}{|l|}{$\mathrm{BMI}\left(\mathrm{kg} / \mathrm{m}^{2}\right)$} \\
\hline$<18$ & $14(27)$ & $14(29)$ & $17(32)$ & 0.45 \\
\hline$>30$ & $15(29)$ & $16(33)$ & $14(26)$ & 0.58 \\
\hline Post-surgery & $23(44)$ & $18(38)$ & $22(42)$ & 0.46 \\
\hline Post-surgery+BMl $<18 \mathrm{~kg} / \mathrm{m}^{2}$ & $2(4)$ & $1(2)$ & $3(6)$ & 0.88 \\
\hline Post-surgery+BMI >30 kg/m² & $4(8)$ & $2(4)$ & $1(2)$ & 0.38 \\
\hline
\end{tabular}

Values are presented as mean or number (\%). 
See "Difficult colonoscopy: air, carbon dioxide, or water insufflation? " on page 299.

Supplementary Table 2. Overall Analysis for Primary and Secondary Endpoints

\begin{tabular}{|c|c|c|c|c|c|c|c|}
\hline End points & $\begin{array}{l}\text { Air insufflation } \\
\quad(n=52)\end{array}$ & $\begin{array}{c}\text { Carbon dioxide } \\
\text { insufflation }(n=48)\end{array}$ & $\begin{array}{l}\text { Water insufflation } \\
\qquad(n=53)\end{array}$ & $P$-value ${ }^{a}$ & $P$-value ${ }^{\mathrm{b}}$ & $P$-value ${ }^{c}$ & $P$-value ${ }^{\mathrm{d}}$ \\
\hline \multicolumn{8}{|l|}{ Pain and sedation } \\
\hline Primary end point & $17(32.7)$ & $21(43.8)$ & 45 (84.9) & $<0.001$ & 0.210 & $<0.001$ & $<0.001$ \\
\hline Pain score & 5.17 & 4.72 & 3.93 & $<0.001$ & 0.090 & $<0.001$ & 0.001 \\
\hline Sedation & $5(9.6)$ & $7(14.6)$ & $2(3.8)$ & 0.110 & & & \\
\hline \multicolumn{8}{|l|}{ Secondary end point } \\
\hline Cecal intubation rate & 45 (86.5) & $37(77.1)$ & 45 (84.9) & 0.450 & & & \\
\hline Cecal intubation time (min) & 23.42 & 23.35 & 21.00 & 0.140 & & & \\
\hline \multicolumn{8}{|l|}{ Pain scores (on VAS) } \\
\hline Rectosigmoid junction & 5.81 & 5.95 & 4.65 & $<0.001$ & 0.860 & $<0.001$ & $<0.001$ \\
\hline Splenic flexure & 6.36 & 5.65 & 4.69 & $<0.001$ & 0.110 & $<0.001$ & 0.018 \\
\hline Hepatic flexure & 3.57 & 3.00 & 2.69 & 0.006 & 0.570 & 0.005 & 0.110 \\
\hline Withdrawal & 1.81 & 1.25 & 1.89 & $<0.001$ & 0.001 & 0.840 & $<0.001$ \\
\hline Abdominal compression & $36(69.2)$ & $29(60.4)$ & 27 (50.9) & 0.160 & & & \\
\hline Change in position & $31(59.6)$ & $32(66.7)$ & $31(58.5)$ & 0.760 & & & \\
\hline
\end{tabular}

Values are presented as number (\%) or mean.

${ }^{a}$ Overall.

${ }^{b}$ Air and carbon dioxide.

'Air and water.

${ }^{\mathrm{d}}$ Carbon dioxide and water.

VAS, visual analogue scale. 
See "Difficult colonoscopy: air, carbon dioxide, or water insufflation? " on page 299.

Supplementary Table 3. Analysis for Primary and Secondary Endpoints $\left(\mathrm{BMI}<18 \mathrm{~kg} / \mathrm{m}^{2}\right)$

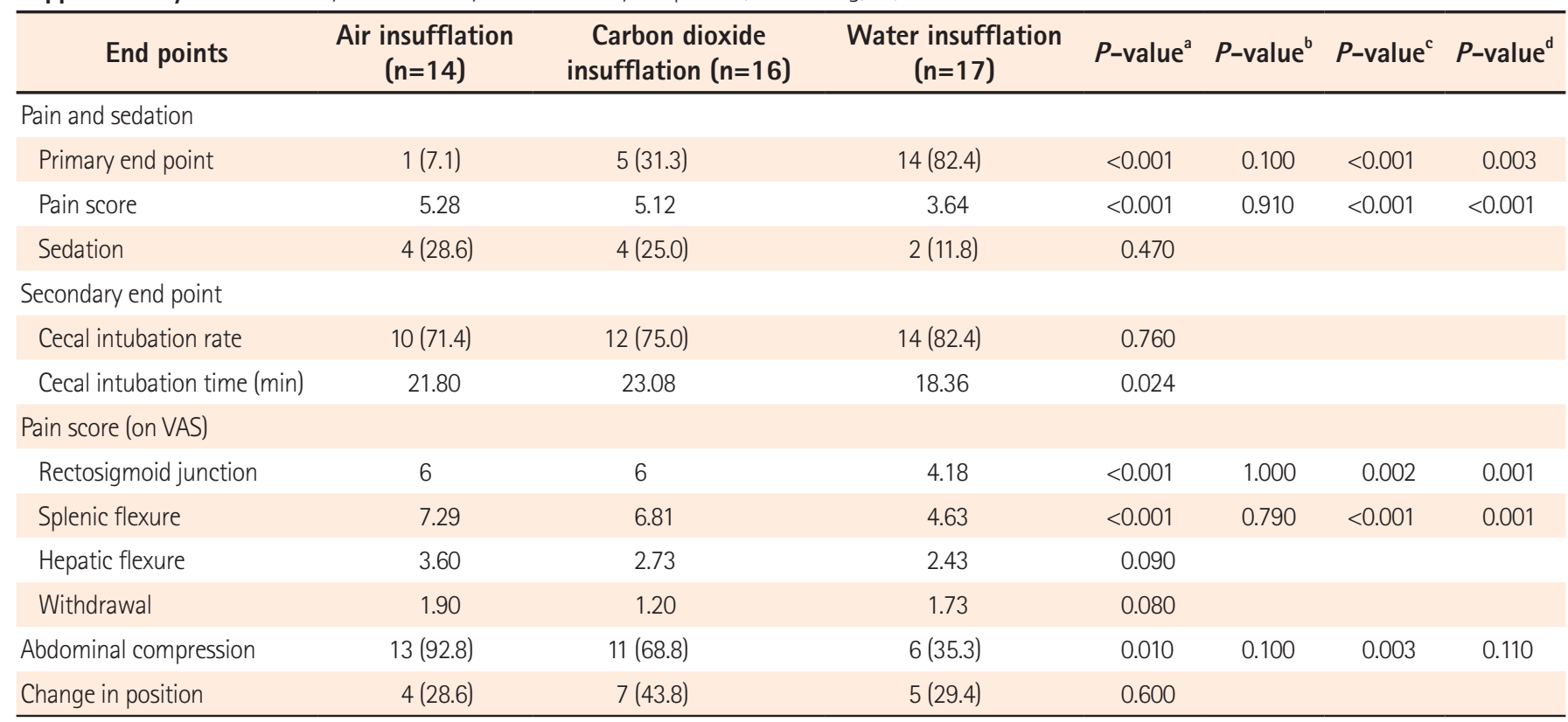

Values are presented as number (\%) or mean.

${ }^{\mathrm{a} O v e r a l l .}$

${ }^{b}$ Air and carbon dioxide.

'Air and water.

${ }^{\mathrm{d}}$ Carbon dioxide and water.

VAS, visual analogue scale. 
See "Difficult colonoscopy: air, carbon dioxide, or water insufflation? " on page 299.

Supplementary Table 4. Analysis for Primary and Secondary Endpoints (BMI $\left.>30 \mathrm{~kg} / \mathrm{m}^{2}\right)$

\begin{tabular}{|c|c|c|c|c|c|c|c|}
\hline End points & $\begin{array}{l}\text { Air insufflation } \\
(n=15)\end{array}$ & $\begin{array}{c}\text { Carbon dioxide } \\
\text { insufflation }(n=16)\end{array}$ & $\begin{array}{l}\text { Water insufflation } \\
\qquad(n=14)\end{array}$ & $P$-value ${ }^{a}$ & $P$-value ${ }^{\mathrm{b}}$ & $P$-value ${ }^{\mathrm{c}}$ & $P$-value ${ }^{\mathrm{d}}$ \\
\hline \multicolumn{8}{|l|}{ Pain and sedation } \\
\hline Primary end point & $7(46.7)$ & $9(56.3)$ & $11(78.6)$ & 0.750 & & & \\
\hline Pain score & 4.92 & 4.22 & 4.11 & 0.100 & & & \\
\hline Sedation & 0 & 0 & 0 & & & & \\
\hline \multicolumn{8}{|l|}{ Secondary end point } \\
\hline Cecal intubation rate & 14 (93.3) & $11(68.8)$ & 12 (85.7) & 0.300 & & & \\
\hline Cecal intubation time (min) & 27.92 & 29.17 & 25.25 & 0.400 & & & \\
\hline \multicolumn{8}{|l|}{ Pain score (on VAS) } \\
\hline Rectosigmoid junction & 5.85 & 5.44 & 5.33 & 0.500 & & & \\
\hline Splenic flexure & 5.62 & 4.78 & 4.33 & 0.015 & 0.163 & 0.016 & 0.715 \\
\hline Hepatic flexure & 3.31 & 3.67 & 3.00 & 0.700 & & & \\
\hline Withdrawal & 1.92 & 1.50 & 2.38 & 0.100 & & & \\
\hline Abdominal compression & $9(60.0)$ & $11(68.7)$ & $9(64.3)$ & 0.870 & & & \\
\hline Change in position & $9(60.0)$ & $11(68.7)$ & $8(57.1)$ & 0.780 & & & \\
\hline
\end{tabular}

Values are presented as number (\%) or mean

${ }^{a}$ Overall.

${ }^{b}$ Air and carbon dioxide.

'Air and water.

${ }^{\mathrm{d}}$ Carbon dioxide and water.

VAS, visual analogue scale. 
See "Difficult colonoscopy: air, carbon dioxide, or water insufflation? " on page 299.

Supplementary Table 5. Analysis for Primary and Secondary Endpoints (Post-Surgery)

\begin{tabular}{|c|c|c|c|c|c|c|c|}
\hline End points & $\begin{array}{l}\text { Air insufflation } \\
\quad(n=23)\end{array}$ & $\begin{array}{c}\text { Carbon dioxide } \\
\text { insufflation }(n=18)\end{array}$ & $\begin{array}{l}\text { Water insufflation } \\
\qquad(n=22)\end{array}$ & $P$-value ${ }^{a}$ & $P$-value ${ }^{b}$ & $P$-value ${ }^{\mathrm{c}}$ & $P$-value \\
\hline \multicolumn{8}{|l|}{ Pain and sedation } \\
\hline Primary end point & $9(39.1)$ & $9(50.0)$ & 17 (77.3) & 0.031 & 0.486 & 0.009 & 0.072 \\
\hline Pain score & 5.11 & 4.80 & 3.81 & $<0.001$ & 0.390 & $<0.001$ & $<0.001$ \\
\hline Sedation & $5(21.7)$ & $4(22.2)$ & $3(13.6)$ & 0.720 & & & \\
\hline \multicolumn{8}{|l|}{ Secondary end point } \\
\hline Cecal intubation rate & $22(95.7)$ & 15 (83.3) & $21(95.5)$ & 0.270 & & & \\
\hline Cecal intubation time (min) & 25.14 & 25.11 & 20.86 & 0.020 & 0.790 & 0.040 & 0.060 \\
\hline \multicolumn{8}{|l|}{ Pain score (on VAS) } \\
\hline Rectosigmoid junction & 5.93 & 5.80 & 4.58 & $<0.001$ & 0.930 & $<0.001$ & 0.003 \\
\hline Splenic flexure & 6.48 & 6.08 & 4.52 & $<0.001$ & 0.610 & $<0.001$ & 0.001 \\
\hline Hepatic flexure & 3.43 & 3.00 & 2.64 & 0.150 & & & \\
\hline Withdrawal & 1.91 & 1.29 & 1.96 & 0.010 & 0.030 & 0.970 & 0.020 \\
\hline Abdominal compression & $14(60.9)$ & $7(38.9)$ & $12(54.5)$ & 0.364 & & & \\
\hline Change in position & $18(78.2)$ & $14(77.8)$ & 18 (81.8) & 0.939 & & & \\
\hline
\end{tabular}

Values are presented as number (\%) or mean.

${ }^{a}$ Overall.

${ }^{b}$ Air and carbon dioxide.

'Air and water.

${ }^{\mathrm{d}}$ Carbon dioxide and water.

VAS, visual analogue scale. 